\title{
0 envelhecimento como um tema da atualidade: a produção de sentidos pela mídia jornalística
}

\author{
Averlândio Wallysson Soares Costa*, Maria do Socorro Costa Feitosa Alves*
}

\section{Resumo}

O estudo busca analisar as produções de sentidos sobre o envelhecimento pelos meios jornalísticos, evidenciando os modos como é percebido e discutido o fenômeno do envelhecimento. A pesquisa é embasada na teoria das representações sociais, utilizando como universo de pesquisa os três principais jornais do estado do Rio Grande do Norte: Tribuna do Norte, Jornal de Hoje e Gazeta do Oeste, sendo avaliados por meio da análise de conteúdo temático de Bardin (2009). É identificada uma expressiva tendência para a explicação do fenômeno envelhecimento, buscando entender as consequências de tal processo para a sociedade. Nota-se uma necessidade em compreender essa nova conjunção social, já que essa é uma demanda que se estabelece na contemporaneidade. Desse modo, torna-se importante compreender os sentidos estabelecidos sobre o envelhecimento que se configuram, de modo a serem construídos valores e juízos mais fidedignos às reais necessidades.

Palavras-chave: Artigo de jornal. Envelhecimento. Produção de sentidos.

\section{Introdução}

O Brasil vive uma intensa mudança demográfica, com acentuadas alterações nos padrões de vida ocorridas ao longo dos anos. A população que tem vivido mais, aumentando o número de idosos na sociedade. Surgem, assim, novas necessidades e novos desafios a serem enfrentados com essa nova caracterização populacional, com a diminuição do número de jovens e o aumento progressivo da população idosa (VERAS, 2008).

Com esse novo contexto, novas situações e realidades fazem-se presentes, exigindo novas habilidades e estruturas sociais, a fim de atender essas novas demandas. Como um fenômeno social, o envelhecimento projeta-se como um campo produtivo de saberes e sentidos, sendo importante perceber como ocorre o processo de produção de sentidos sobre o envelhecimento, já que é por meio desse

* Graduado em Enfermagem pela UERN. Mestre em Saúde Coletiva pela UFRN. Endereço para correspondência: Avenida dos Caipós, 121/607, T3, Pitimbu, Natal, RN. CEP: 59067-400. E-mail: averlandiowallysson@ hotmail.com

** Graduada em Odonotologia pela UFRN. Pós-doutoramento no ISCTE da Universidade de Lisboa. E-mail:socorrocfa@hotmail.com

$\rightarrow$ http://dx.doi.org/10.5335/rbceh.v14i3.6460

Recebido em: 22.10.2016. Aceito em: 15.01.2018. 
processo que valores e importâncias são estabelecidos (WHITAKER, 2010).

Com a nova realidade contemporânea, a sociedade tenta expressar e entender essa nova situação; desse modo, as formas de produção de sentidos atuam justamente como meio de sanar essas necessidades de conhecimento e (re) construir essas realidades.

Na contemporaneidade, não há como deixar de frisar o decisivo papel que os meios midiáticos exercem nos modos de produção de sentidos e, assim, nos valores e importâncias dados aos seres e às coisas na sociedade. Com o envelhecimento não é diferente: como tema atual na sociedade, a mídia se interessa por abordar em seus produtos a temática envelhecimento e, assim, atua como instrumento de produção de sentidos, ditando opiniões e condutas em sociedade (VERAS, 2008).

Faz-se importante, assim, refletir sobre os modos de produção de sentido acerca do envelhecimento pela mídia. Entre os instrumentos midiáticos, pelo seu poder de disseminação e pelo seu caráter informativo, os meios jornalísticos são importantes espaços de construção de informação, disseminando e discutindo os mais variados temas. Nesse sentido, algumas inquietações se fazem necessárias: como os meios jornalísticos discutem o fenômeno envelhecimento na atualidade? E como o envelhecimento é tratado?

Dessa forma, com o presente estudo, buscou-se analisar as produções de sentidos sobre o envelhecimento pelos meios jornalísticos, de modo a perceber como eles discutem e explicam esse fenômeno, por meio dos formatos on-line dos três principais jornais do estado do Rio Grande do Norte: Tribuna do Norte, Jornal de Hoje e Gazeta do Oeste.

\section{Materiais e métodos}

Este trabalho insere-se na hermenêutica de pesquisas norteadas por pressupostos epistemológicos construtivistas, utilizando a teoria das representações sociais, que são modalidades de conhecimento prático orientado para a compreensão do mundo e para a comunicação, ou seja, formas de conhecimento que orientam as práticas cotidianas, oriundas das forças dos conteúdos que circulam em nossa sociedade e das forças decorrentes do próprio processo de interação social e das pressões para definir uma dada situação de forma a confirmar e a manter identidades coletivas. Desse modo, não se leva em consideração o indivíduo isolado, mas as respostas individuais, enquanto manifestações de tendências do grupo ao qual pertencem ou participam (MOSCOVICI, 2011).

As representações sociais são consideradas expressões da realidade interindividual, estruturas que possibilitam o poder da criação e da transformação da realidade social. São formas de conhecimento que se manifestam como elementos cognitivos, mas não se reduzem apenas a esses elementos, pois, sendo socialmente elaboradas e compartilhadas, contribuem para a construção de uma realidade comum que possibilita a comunicação (MOSCOVICI, 2011). 
Quanto ao universo de estudo, o trabalho deteve-se nos três principais jornais do estado do Rio Grande do Norte: Tribuna do Norte, Jornal de Hoje e Gazeta do Oeste. Tais instrumentos midiáticos representam importantes meios de disseminação e construção de opiniões em todo o estado, discutindo temáticas regionais e nacionais.

Para a coleta do corpus da pesquisa, o estudo deteve-se às versões on-line dos jornais citados, consultando os sites dos próprios jornais. Utilizando os locais de pesquisa dos sites, buscou-se pelos termos: envelhecimento e idoso. Detendo-se as notícias publicadas no período entre 2012 e 2014, após leitura de todas as matérias resultantes da busca, selecionaram-se cinco notícias que tentavam explicar o processo de envelhecimento e seus impactos para a sociedade, já que esse é o objetivo do estudo.

As cinco notícias contempladas são as seguintes, descritas por suas manchetes: Viver e envelhecer no Século 21 (JORNAL TRIBUNA DO NORTE, 2012); Brasil do futuro terá mais idosos que crianças (JORNAL TRIBUNA DO NORTE, 2013); Brasil caminha para se tornar um país de idosos já em 2030, aponta IBGE (JORNAL DE HOJE, 2013); Cresce inadimplência nos financiamentos aos idosos (JORNAL TRIBUNA DO NORTE, 2014a); Governo amplia prazo para pagamento de consignado por aposentados e pensionistas (JORNAL TRIBUNA DO NORTE, 2014b).

Salienta-se que, mesmo de forma particular, os meios jornalísticos incluídos neste estudo representam importantes instrumentos de disseminação de informações, que ao longo do tempo contribuíram para a construção de opiniões e ideários disseminados para os diferentes grupos sociais do estado e da região. Ao optar-se pelo formato on-line dos jornais, buscou-se trabalhar com os meios mais acessíveis e populares desses jornais, já que, com o incremento das redes de computadores, tais informações/notícias são compartilhadas quase que instantaneamente entre os leitores (VALA, 1993).

Como técnica para a análise de dados, foi utilizada a análise de conteúdo temático de Bardin (2009), detendo-se além do evidente, nas entrelinhas, nos subentendidos e nas polissemias possíveis. Para entender os sentidos construídos em meio social, considerou-se a indissociabilidade entre o discurso e o autor (BARDIN, 2009).

\section{Resultados e discussão}

Sobre a temática envelhecimento, presencia-se uma discussão cada vez mais forte na sociedade, seja pela própria mudança do perfil populacional, que tende ao aumento do número de idosos, seja pela conjuntura social, que tendeu à pouca discussão, até então, sobre esse tema.

As questões referentes à velhice e ao processo de envelhecimento têm despertado cada vez mais interesse da sociedade de um modo geral, em função do acelerado processo de envelhecimento populacional que vem ocorrendo em vários países, inclusive no Brasil (HEIN; ARAGAKI, 2012, p. 2142).

Os meios midiáticos, como reflexo dos modos de produção e reprodução social, retratam tais discussões em seus 
instrumentos. Nos jornais impressos do Rio Grande do Norte, essa discussão também é noticiada, evidenciando a utilidade e a presença do assunto entre os temas explorados nos jornais.

$\mathrm{O}$ ano de publicação também deve ser levado em consideração e ser objeto de comentários, pois, do levantamento, houve apenas uma notícia em 2012, duas em 2013 e duas em 2014, o que representa 0 aumento progressivo das discussões sobre envelhecimento com o passar dos anos, embora ainda sejam muito escassas. As cinco matérias elegidas são dos jornais de maior circulação na capital do estado: Tribuna do Norte e Jornal de Hoje, o que pode indicar maior presença da discussão em grandes centros urbanos, onde são mais perceptíveis as mudanças oriundas do envelhecimento, como as mudanças nos padrões de consumo e produção (SIQUEIRA; BOTELHO; COELHO, 2002).

Em matéria do Jornal de Hoje, de 2013, há a seguinte manchete: Brasil caminha para se tornar um país de idosos já em 2030, aponta IBGE. Tal noticiário demonstra, por meio de dados estatísticos de órgãos nacionais, a mudança do perfil populacional do país, que, seguindo os rumos de outros países, vem aumentando consideravelmente a expectativa de vida e, consequente, o número de idosos.

O aumento do número de anos é decorrente da redução nas taxas de fertilidade e do acréscimo da longevidade nas últimas décadas. Em todo o mundo, observam-se quedas abruptas nas taxas de fertilidade (SCHNEIDER; IRIGARAY, 2008, p. 586).
Em trecho da matéria, lê-se: "Os dados do IBGE mostram ainda que a principal fonte de rendimento dos idosos de 60 anos ou mais foi a aposentadoria ou a pensão, equivalendo a $66,2 \%$, e chegando a $74,7 \%$ no caso do grupo de 65 anos ou mais" (JORNAL DE HOJE, 2013, não paginado); essas constatações são reforçadas por outro trecho:

[...] hoje em dia a população de idosos que recebe benefícios é muito expressiva, [...] o sistema previdenciário tem que estar atento ao envelhecimento (JORNAL DE HOJE, 2013, não paginado).

O trecho remete à discussão acerca da condição de inatividade relacionada ao envelhecimento. No contexto neoliberal e capitalista atual, a condição de produção denota a importância dada ao ser, que é oriunda do quanto se produz. Traz a condição de gasto e o ônus que o envelhecimento pode representar aos cofres públicos (SCHNEIDER; IRIGARAY, 2008).

Os velhos aumentam em número e longevidade, o que municia certos gestores sociais a argumentar que isto pode levar a "quebra" do sistema previdenciário e pôr em perigo a própria reprodução da sociedade (MOTTA, 2010, p. 234).

Em outra matéria do jornal Tribuna do Norte, é vinculada a seguinte manchete: Brasil do futuro terá mais idosos que crianças (2013), que traz projeções estatísticas sobre o aumento acentuado de idosos em relação aos mais jovens, destacando as transformações de cunho social, como taxa de fecundidade, taxa de natalidade e expectativa de vida, conforme trecho: 
[...] o país do futuro terá mais idosos que crianças, mais mortes que nascimentos, mulheres que decidem ser mães mais velhas e menos desigualdades regionais (TRIBUNA DO NORTE, 2013, não paginado).

O aumento da população de idosos, já verificado nos países desenvolvidos, também vem se constituindo tema emergente no Brasil. Esse fato induz discussões sobre os mais diversos aspectos, e a mídia, por sua vez, participa desse processo de transição demográfica (GORZONI; PIRES, 2010).

Outra matéria do jornal Tribuna do Norte traz a seguinte manchete: Viver e envelhecer no século 21 (2012), em que são discutidas a construção e as características do envelhecimento na sociedade atual. Na matéria, define-se o idoso do século XXI como:

Uma população com mais de 60 anos, economicamente plena e ainda cheia de saúde para aproveitar a vida. Porém, a velhice é difícil, especialmente numa sociedade como a nossa que, a todo instante, desrespeita os idosos e é obcecada pelo mito da eterna juventude (TRIBUNA DO NORTE, 2012, não paginado).

O trecho corrobora com a discussão atual de que a população vivendo mais, ficando mais velha, encontra uma sociedade pouco preparada para o envelhecimento, para atender de forma peculiar às verdadeiras necessidades desse público, de tal modo que muitas vezes "estereótipos negativos [são] atribuídos pelos próprios idosos, que não se reconhecem como tal e falam categoria 'velho' como senão fizessem parte" (SCHNEIDER; IRIGARAY, 2008. p. 587). É necessário, pois, elucidar melhor tais temáticas, haja vista que

[...] as concepções de velhice nada mais são do que resultado de uma construção social e temporal feita no seio de uma sociedade com valores e princípios próprios, que são atravessados por questões multifacetadas, multidirecionadas e contraditórias. $\mathrm{Na}$ época contemporânea, florescer do século XXI, ao mesmo tempo em que a sociedade potencializa a longevidade, ela nega aos velhos o seu valor e sua importância social. Vive-se em uma sociedade de consumo na qual apenas o novo pode ser valorizado, caso contrário, não existem produção e acumulação de capital (SCHNEIDER; IRIGARAY, 2008. p. 587).

Em duas matérias do jornal Tribuna do Norte de 2014, tem-se a discussão de meios explicativos de entendimento sobre o envelhecimento populacional. Na matéria intitulada Envelhecimento: entenda mais sobre o assunto, observa-se o estabelecimento de uma explicação única do envelhecimento, visto como uma questão biológica, conforme o trecho:

Diversas são as alterações fisiológicas decorrentes do processo de envelhecimento. Dentre elas, na visão há a diminuição da acuidade visual; na audição e sistema vestibular há a diminuição do equilíbrio e discriminação de sons; no paladar há diminuição na sensação gustativa; no olfato há diminuição na percepção de odores; no tato e propriocepção há diminuição da propriocepção articular e da sensibilidade táctil de mãos e pés (JORNAL TRIBUNA DO NOR$\mathrm{TE}, 2014 \mathrm{~b}$, não paginado).

Isso é reafirmado com outro trecho:

Além das alterações fisiológicas do envelhecimento, muitos idosos apresentam mudanças relacionadas a doenças crônico-degenerativas (TRIBUNA DO NORTE, 2014b, não paginado). 
Os trechos reportam uma condição limitada sobre o que é o envelhecimento, de modo que é vista apenas uma interface do processo: os fatores biológicos. Essa perspectiva vai de encontro ao que representa o meio social, estabelecendo uma visão biológica para explicar todos os fatores da vida e do corpo dos seres (GORZONI; PIRES, 2010).

$\mathrm{Na}$ matéria Mais velhos, mais jovens, é construída uma analogia entre velhice e jovialidade: "[...] esteja chegando o tempo de ver que os mais velhos podem continuar bem jovens!" (JORNAL TRIBUNA DO NORTE, 2014a, não paginado). Essa condição se estabelece por meio da negação da velhice presente na sociedade, haja vista que a velhice é tida como uma condição biológica, entendida como momento de finitude, de poucas possibilidades e muitas limitações, o contrário de jovialidade, motivo de saúde, descobertas e alegrias (GORZONI; PIRES, 2010). Da dimensão biológica, "o envelhecimento foi associado à deterioração do corpo e, em consequência, tratado como uma etapa da vida caracterizada pelo declínio" (UCHÔA, 2003, p. 850).

$\mathrm{Na}$ atual conjuntura social, tem-se estabelecido uma relação dualizada sobre o envelhecimento: ao mesmo tempo em que se percebe o envelhecimento da população como um todo, verifica-se uma preocupação tão somente com o ônus que isso possa gerar, com as consequências que isso vai acarretar para a economia, pouco se importando com o fato de se conhecer as verdadeiras necessidades desse público (NOTARI; FRAGOSO, 2011).
Enquanto nos mantivermos limitados a entender o envelhecimento por meio de processos individualizados e independentes, e não for dado espaço para a compreensão complexa que o tema exige, não desenvolveremos entendimentos fidedignos nem ações condizentes às realidades e às necessidades.

\section{Considerações finais}

É notório o incremento das discussões sobre envelhecimento na esfera social; a mídia, como instrumento desse meio e processo da sociedade, vem acompanhando o aumento de tais debates, tornando-se importante refletir sobre esses aspectos.

A representação social dos meios jornalísticos acerca do envelhecimento é uma temática cada vez mais presente. Nos jornas analisados neste estudo, é percebida a evidência dada ao assunto, permitindo, assim, a construção de sentidos e posturas sobre o tema.

Nesse sentido, as construções sobre envelhecimento seguem entendimentos construídos socialmente, representando necessidades desse meio social. O que a mídia discute é estabelecido por meio das interações e construções realizadas pela sociedade, sendo produto e meio da transformação social.

O envelhecimento, como um fenômeno social, também acompanha tais transformações. A busca por entender o fenômeno do envelhecimento, as novas estruturas organizativas da sociedade é, assim, motivo de reflexão e compreensão na coletividade. 


\section{Ageing as theme of news: the production of directions for journalism media}

\section{Abstract}

The study aims to analyze the meaning productions abouth aging by the news media, showing the ways in which they are perceived and discussed this phenomenon. The research is based in the theory of Social Representations, using as research universe the three main newspapers of Rio Grande do Norte State: Tribuna do Norte, Jornal de Hoje and Gazeta do Oeste, and analyzed by qualitative analysis of Bardin (2009). It is identified a significant trend for the explanation of the aging phenomenon, seeking out to understand the consequences of this process for the society. Notes a need to understand this new social conjunction, as this is a demand that is established in contemporary times. Thus, it becomes important to understand the meanings settled dwon abouth the aging that are configured, so as to be constructed more reliable judgment values and the actual needs.

Keywords: Aging. Meaning production. Newspaper article.

\section{Referências}

BARDIN, L. Análise de Conteúdo. Lisboa, Portugal: Edições 70, 2009.

GORZONI, M. L; PIRES, S. L. Há evidências científicas na medicina antienvelhecimento? Anais Brasileiros de Dermatologia, Rio de Janeiro, v. 85, n. 1, p. 57-64, 2010.

HEIN, M. A; ARAGAKI, S. S. Saúde e envelhecimento: um estudo de dissertações de mestrado brasileiras (2000-2009). Ciência e Saúde Coletiva, Rio de Janeiro, v. 17, n. 8, p. 2141-2150, ago. 2012.
JORNAL DE HOJE. Brasil caminha para se tornar um país de idosos já em 2030, aponta IBGE. 2013. Disponível em: <http:// jornaldehoje.com.br/brasil-vai-se-tornar-um-pais-de-idosos-ja-em-2030/>. Acesso em: 21 nov. 2015.

JORNAL TRIBUNA DO NORTE. Brasil do futuro terá mais idosos que crianças. 2013. Disponível em: <http://www.tribunadonorte. com.br/noticia/brasil-do-futuro-tera-mais-idosos-que-criancas $/ 259798<$. Acesso em: 21 nov. 2015.

JORNAL TRIBUNADO NORTE. Cresce inadimplência nos financiamentos aos idosos. 2014a. Disponível em: <http://tribunadonorte.com.br/noticia/cresce-inadimpla-ncia-nos-financiamentos-aos-idosos/298167>. Acesso em: 21 nov. 2015.

JORNAL TRIBUNA DO NORTE. Governo amplia prazo para pagamento de consignado por aposentados e pensionistas. $2014 \mathrm{~b}$. Disponível em: <http://tribunadonorte.com. br/noticia/governo-amplia-prazo-para-pagamento-de-consignado-por-aposentados-e-pensionistas/294438>. Acesso em: 21 nov. 2015.

JORNAL TRIBUNA DO NORTE. Viver $e$ envelhecer no século 21. 2012. Disponível em: <http://tribunadonorte.com.br/noticia/ viver-e-envelhecer-no-seculo-21/220824>. Acesso em: 21 nov. 2015.

MOSCOVICI, S. Representações sociais: investigações sobre psicologia social. 8. ed. Petrópolis, RJ: Vozes, 2011.

MOTTA, A. B. A atualidade do conceito de gerações na pesquisa sobre o envelhecimento. Sociedade e Estado, Brasília, v. 25, n. 2, p. 225-250, maio/ago. 2010.

NOTARI, M. H. A.; FRAGOSO, M. H. J. M. M. A inserção do Brasil na política internacional de direitos humanos da pessoa idosa. Revista Direito Getúlio Vargas, São Paulo, v. 7, n. 1, p. 259-276, jan./abr. 2011. 
SCHNEIDER, R. H.; IRIGARAY, T. Q. O envelhecimento na atualidade: aspectos cronológicos, biológicos, psicológicos e sociais. Estudos de Psicologia, Campinas, v. 25, n. 4, p. 585-593, out./dez. 2008.

SIQUEIRA, R. L.; BOTELHO, M. I. V.; COELHO, F. M. G. A velhice: algumas considerações teóricas e conceituais. Ciência e Saúde Coletiva, Rio de Janeiro, v. 7, n. 4, p. 899-906, abr. 2002.

UCHÔA, E. Contribuições da antropologia para uma abordagem das questões relativas à saúde do idoso. Cadernos de Saúde Pública, Rio de Janeiro, v. 19, n. 3, p. 849-853, maio/ jun. 2003.

VALA, J. Representações sociais: para uma psicologia social do pensamento social. In: VALA, J.; MONTEIRO, M. B. (Org.). Psicologia Social. Lisboa: Fundação Calouste Gulbenkian, 1993. p. 164-177.

VERAS, R. P. et al. A assistência suplementar de saúde e seus projetos de cuidado para com o idoso. Ciência e Saúde Coletiva, Rio de Janeiro, v. 13, n. 4, p. 1119-1126, ago. 2008.

WHITAKER, D. C. A. O idoso na contemporaneidade: a necessidade de se educar a sociedade para as exigências desse "novo" ator social, titular de direitos. Cadernos do Centro de Estudos Educação e SociedadeCEDES, Campinas, v. 30, n. 81, p. 179-188, maio/ago. 2010. 